In der Rubrik „Literatur kompakt" werden die wichtigsten Originalarbeiten aus der internationalen Fachliteratur referiert.

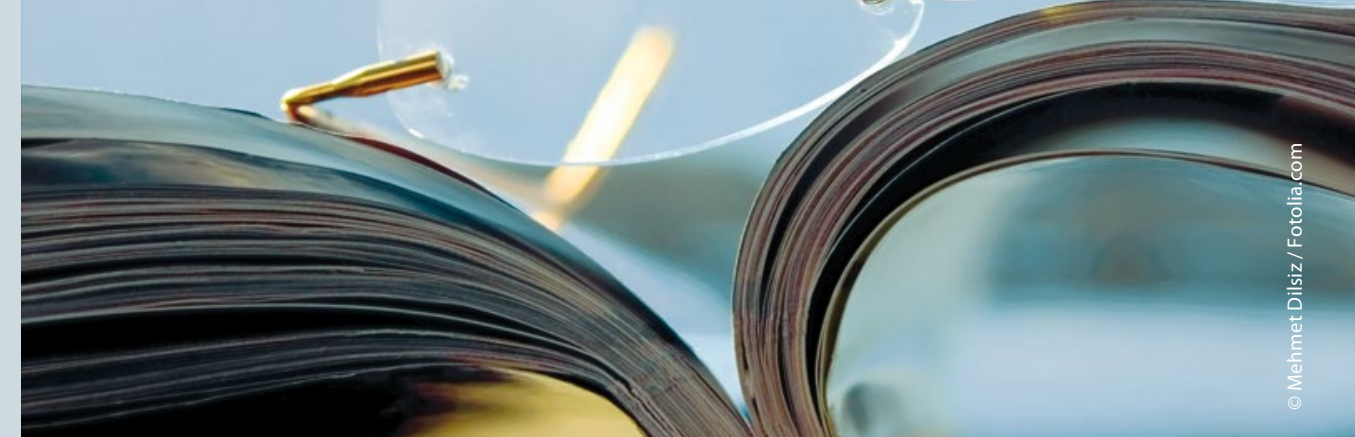

\section{Gräserpollenzahl und Immunreaktion korrelieren nur mäßig}

\section{Die Gräserpollenzahl in der Luft korreliert nicht konstant mit einem} bestimmten Allergengehalt. Die immunologische Messung des Luftallergengehalts wäre deshalb bei bestimmten Fragestellungen eine Alternative zur Pollenzählung. Eine aktuelle Studie stellte beide Methoden gegenüber.

$B_{k}^{e}$ ei den meisten Gräserpollenallergikern spielen Phl p 1 und 5 die wichtigste Rolle, wobei Phl p 5a aufgrund seiner guten Charakterisierung und hohen Allergenität mittlerweile als Referenzallergen für Diagnostik und Allergenstandardisierung von Extrakten zur spezifischen Immuntherapie (SIT) weithin akzeptiert ist. Die immunologisch basierte Messung des Phl-p-5-Gehalts eignet sich auch als Parameter für Aus- sagen zum Allergengehalt der Außenluft und ist damit bei bestimmten allergologischen Fragestellungen eine Alternative zur klassischen Pollenzählung. Denn schon seit Längerem ist bekannt, dass eine bestimmte Anzahl der Süßgräserpollen eine variable Anzahl klinisch relevanter Allergene freisetzt unter anderem abhängig von Jahreszeit, Wetterlage und geografischer Region. In einer europaweiten Studie wurden des-

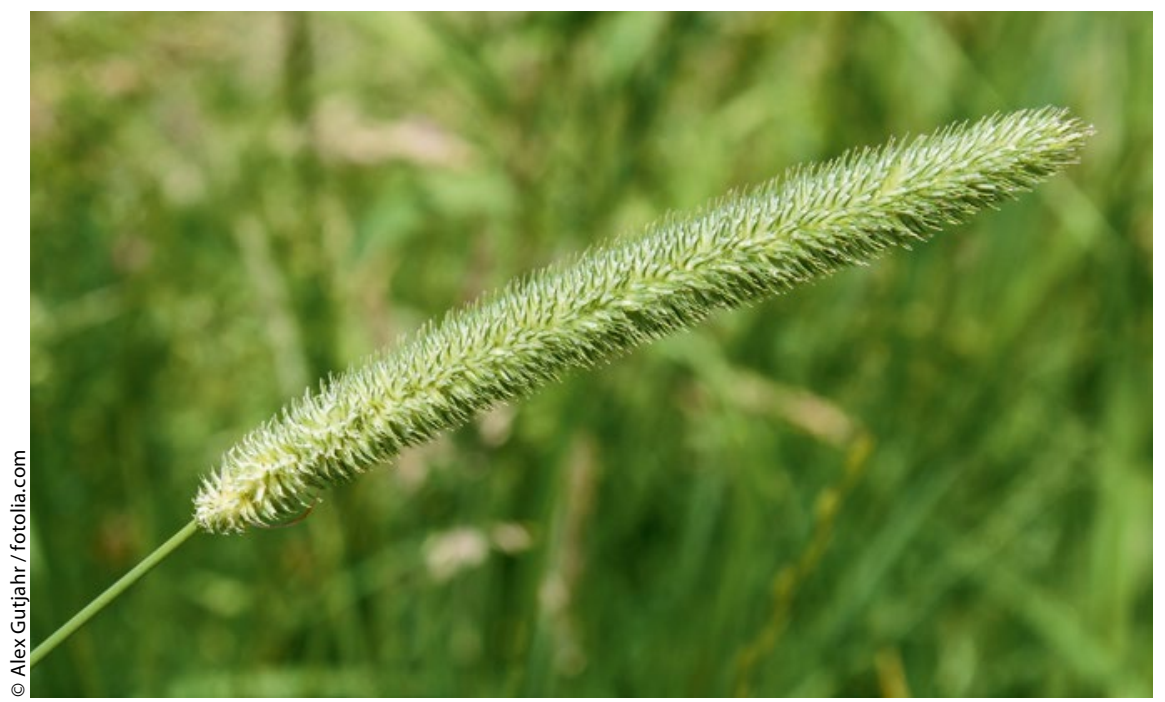

Wiesenlieschgras: Der Allergengehalt und nicht so sehr die Pollenzahl der Außenluft scheint für die allergenspezifische Immunreaktion eine Rolle zu spielen.

halb über drei Jahre an zehn Standorten Pollen mit einer volumetrischen Pollenfalle eingefangen und gezählt, sowie der Phl-p-5-Gehalt in zwei per Kaskadenimpaktor gesammelten Partikelfraktionen $(>10 \mu \mathrm{m}$ und $>2,5 \mu \mathrm{m})$ mithilfe eines spezifischen ELISA bestimmt. Die Ergebnisse wurden miteinander korreliert und abhängig vom Standort katalogisiert.

Im Durchschnitt setzte eine Süßgräserpolle 2,3 pg Phl p 5 frei - allerdings mit einer großen Streubreite von weniger als 1 bis zu 9 pg/Polle. Der Allergengehalt schwankte tages-, jahreszeitenund jahresabhängig und war in den einzelnen Regionen unterschiedlich. Die Mediatorfreisetzung im Basophilen-Degranulationsassay mit FceRI-humaniserten Basophilen korrelierte eher mit der Allergenkonzentration als mit der Pollenzahl. Insbesondere bei erhöhter Feuchtigkeit stieg der Allergengehalt in der Fraktion mit den kleinen Partikeln, in denen sich keine Pollen befanden. Die Allergene dieser Fraktion dringen möglicherweise tiefer in die Atemwege ein als Partikel mit einem Durchmesser von $>10 \mu \mathrm{m}$.

Fazit: Die gräserallergenspezifische Immunreaktion korreliert eher mit dem Allergengehalt als mit der Pollenzahl der Außenluft. Bei bestimmten allergologischen Fragestellungen, etwa im Rahmen von klinischen oder epidemiologischen Studien könnte deshalb die Allergenmessung Vorteile bringen.

\section{Dr. Barbara Kreutzkamp}

Buters J et al. Variation of the group 5 grass pollen allergen content of airborne pollen in relation to geographic location and time in season. J Allergy Clin Immunol 2015;136:87-95.e6 